\title{
Behavior of Self-Compacting Reinforced Concrete Dapped End Beams
}

\author{
Qasim M. Shakir ${ }^{1} \&$ Ruqyia Alliwe² \\ ${ }^{1}$ Asst. Prof. University of Kufa, Iraq \\ ${ }^{2}$ Ruqyia Alliwe, Msc. University of Kufa, Iraq \\ Correspondence: Qasim M. Shakir, Asst. Prof. University of Kufa, Iraq. E-mail: qasimm.alabbasi@uokufa.edu.iq, \\ h_f186@yahoo.com
}

Received: January 6, 2019; Accepted: March 3, 2019; Published: March 24, 2019

\begin{abstract}
Dapped end is an essential part of the precast concrete industry, but its unusual shape made it complex in design and sensitive to stresses. It may be needed to upgrade such elements due to errors in design; over loading or the deterioration of members due to severe environments. The concept of dapped-end beams is extensively used in precast concrete construction as buildings, parking structures, bridge girder and recently in footings. It provides better lateral stability and reduces overall height of the structure and to match with geometry of corbel or bracket. In the present work, an experimental study has been conducted to investigate of reinforced SCC dapped beams. The program consists of testing 5-specimens with dimension $(200 \times 400 \times 1600 \mathrm{~mm})$, and two values of $(\mathrm{a} / \mathrm{d})(1.5$, 1.0) under effect of a single point load. Two of samples that have been tested have been significantly tested as controller specimens as a full reinforced., also three beams have been reduced the Hanger and Nib reinforcement. It is found that the $(\mathrm{a} / \mathrm{d})$ ratio has a noticeable effect on the behavior of dapped end beam. So, the tested control beams (full reinf.), the reduction of (a/d) from (1.5) to (1.0), due to improve the failure load by (48\%) with shifted the type of failure from the diagonal at extended end to the diagonal in the re-entry corner. Also, it is found that the reduction of hanger reinf. $(40 \%)$, resulted reduction of the failure $(6 \%)$ for $(\mathrm{a} / \mathrm{d})$ equal 1 value, higher deflection at failure about (18\%). Also, reduction of the nib reinforcement by about $(50 \%)$, results reduction in capacity of the failure load by about (12\%) for $\mathrm{a} / \mathrm{d}=1.5$ and $(12.4 \%) \%$ ) for $\mathrm{a} / \mathrm{d}=1.0$.
\end{abstract}

Keywords: Dapped ends, NSM steel bars, Self-compacting, Strengthening, Diagonal cracking

\section{Introduction}

It is known that precast concrete appeared in the last century, then; its uses have increased dramatically because of its features. This type of construction depends on the regular casting of pieces of concrete and then delivering them to end destination of installation (the site). The points of linkage between the various elements are called connections which. one of the significant elements that should be look in designing of this one of structures. The types of connections use corbels and beams with (DEB) (Liem, 983). The dapped beam is precast concrete beam with reduce the depth at end. However, as the flow of internal forces is interrupted by the sudden change in geometry, regions of disturbances in the flow of these forces are created around the re-entrant corner and in the nib. These regions are referred to as "disturbed regions". To treat such regions two methods were suggested, which are shear friction method (PCI) (Precast Prestressed Concrete Institute, 2010) and STM model (Ahmad, Elahi, Hafeez, Fawad \& Ahsan, 2013).

Such zones may be subjected to high stresses as well as to unforeseen forces such as horizontal force due to temperature changes. These connections are usually located at the inflection points; thus, the moment is reduced, and the corresponding emotion is strengthened. Besides, dapped end allows getting a better fabrication with columns in connection. They are also used to reduce the overall height of the structure and increase stability to support the bearing. They are usually used very heavily in reinforced concrete structures such as prefabricated buildings, parking structures and recently in prefabricated conveyor belts the bridge girder, precast footings (Atta, \& Taman, 2016).

Many researchers studied the behavior and strengthening of reinforced concrete DEB. Such studies discussed the effect of the most influencing parameters on behavior of dapped beam. (Mattock, \& Chan, 1979) concluded that the use of the corbel design concepts in dapped end is valid for $(\mathrm{a} / \mathrm{d}<1)$ but with adding hanger reinforcement. (Liem, 983) showed that the ultimate strength of dapped end with $\left(45^{\circ}\right)$ inclined reinforcement two times the 
strength of the case with horizontal or vertical reinforcement". (Nanni, \& Huang, 2002) investigated the validation of using several alternatives of reinforcement to satisfy the requirement of dapped end design according to PCI. (Lu, Lin, Hwang, \& Lin, 2003) studied several variables that may influence on the behavior, such as the concrete strength, $(\mathrm{a} / \mathrm{d})$ value, and amount of main reinforcement. Tests results showed that the shear strength increased with the increase of the concrete strength, the amount of main reinforcement, and the decrease of $(\mathrm{a} / \mathrm{d})$. (Ahmad, Elahi, Hafeez, Fawad \& Ahsan, 2013) reported that the design for DEB using STM model gave varying results with changes in the angle of strut inclination. (Aswin, Mohammed, Liew \& Syed, 2015) studied Several variables as amount of the nib reinforcement, main flexural reinforcement, and concrete type at the dapped end region. It was found that the use of such compendious composite in the dapped area improved the failure load by (51.9\%). While increasing the amount of nib and main flexural reinforcements enhanced the failure load by $(62.2 \%)$ and (46.7\%) respectively.

(Herzinger \& Elbadry, 2007) Investigated experimentally the behavior of DEB using three analytical methods these being. The STM models. The shear friction method and diagonal bending method. (Iraqi Specification, 1984) considered prestressed concrete beam with DEB various reinforcing schemes have been tested, to study the influence of several parameters on behavior of dapped end as the pre-stressing of the nib, concrete strength, web shear reinforcement, nib height, and splice length of the hanger reinforcement.

\section{Experimental Program}

In the present work, an experimental study has been conducted to describes the outline work carried out in the present study to investigate the behavior for Self-Compacting RC dapped end have been tested under static loads. The program consists of testing five specimens each of dimensions $(200 \times 400 \times 1600 \mathrm{~mm})$ with two values of $(\mathrm{a} / \mathrm{d})$ namely (1.0 and 1.5) Two control samples no reduction (reinforcement 100\%) with two (a/d) values of (1 and 1.5). Three beams with reduce reinf. In the hanger and nib zone.

\section{Materials Properties}

The properties of materials, used in the experimental work are presented in this section. Such materials are cement, water, course aggregate (gravel), fine aggregate (sand), limestone powder, super plasticizer, steel bars and Epoxy. All tests except steel are achieved at the Structural Laboratory in the Department of Civil Engineering / Faculty of Engineering / Kufa University. The staff of the laboratory department/ Bureau consultant of university of kufa performed steel tests.

\subsection{Cement}

The Portland cement (Type I). the manufactured of this cement by (KAR) supplier for cement production (NajafIraq) and conformed to the Iraqi Specifications (IQ.S. 5/1984) (Iraqi Specification, 1984) was used. The chemical and physical analyses of this cement are shown in Tables (1) and (2) respectively.

Table 1. Chemical Composition of Cement

\begin{tabular}{llll}
\hline Oxide Composition & $\mathrm{Abbreviation}$ & Content by Weight (\%) & Limit of (IQ.S. 5/1984) \\
\hline Lime & $\mathrm{CaO}$ & 62.43 & - \\
Silica & $\mathrm{SiO}_{2}$ & 19.36 & - \\
Alumina & $\mathrm{Al}_{2} \mathrm{O}_{3}$ & 4.86 & - \\
Iron Oxide & $\mathrm{Fe}_{2} \mathrm{O}_{3}$ & 3.32 & - \\
Magnesia & $\mathrm{MgO}$ & 3.08 & $5.0(\max )$ \\
Sulfate & $\mathrm{SO}_{3}$ & 2.29 & $2.8(\max )$ \\
Free Lime & - & 1.23 & $4.0(\max )$ \\
Loss of Ignition & L.O.I. & 4 & $4.0(\max )$ \\
Insoluble Residue & I.R. & 1.32 & $1.5(\max )$ \\
Lime Saturation Factor & L.S.F. & 0.96 & $(0.66-1.02) \%$ \\
\hline
\end{tabular}


Table 2. Physical Properties of the Cement

\begin{tabular}{lcc}
\hline \multicolumn{1}{c}{ Physical Properties } & Test Results & Limit of (IQ.S. 5/1984) \\
\hline Specific Surface Area (Blaine Method). $\left(\mathrm{m}^{2} / \mathrm{kg}\right)$ & 348 & $230(\mathrm{~min})$ \\
Setting Time (Vicat's Apparatus) & $1: 52$ & $0: 45(\mathrm{~min})$ \\
Initial Setting Time (hrs:min.) & $3: 36$ & $10: 00(\mathrm{max})$ \\
Final Setting Time (hrs:min.) & & \\
Compressive Strength (MPa) & 24.30 & $15(\mathrm{~min})$ \\
3 days & 30.25 & $23(\mathrm{~min})$ \\
7 days & & \\
\hline
\end{tabular}

\subsection{Water}

Potable water is used for both mixing and curing purpose.

\subsection{Fine Aggregate (Sand)}

Natural sand taken from Al-Ukhaidur region, was used in concrete mix. Test results showed that the used sand complies with the requirements of the Iraqi Standard Specifications NO.45/1984 (Iraqi Specification, 1984) as illustrated in Table (3) and Table (4) for grain size analysis and physical properties respectively.

Table. 3 Grading of Fine Aggregate

\begin{tabular}{lll}
\hline Physical Properties & Test Results & Limit Specification \\
\hline Specific Gravity & 2.56 & - \\
Sulfate Content & $0.09 \%$ & $\leq 0.5 \%$ \\
Absorption & $0.73 \%$ & - \\
\hline
\end{tabular}

Table 4. Physical Properties of Fine Aggregate

\begin{tabular}{ccc}
\hline Sieve Size $(\mathrm{mm})$ & Cumulative Passing (\%) & Limit of (IQ.S. 45/1984). zone 2 \\
\hline 4.75 & 100 & $90-100$ \\
2.36 & 90.4 & $75-100$ \\
1.18 & 81.9 & $55-90$ \\
0.6 & 57.9 & $35-59$ \\
0.3 & 16.9 & $8-30$ \\
0.15 & 2 & $0-10$ \\
\hline
\end{tabular}

\subsection{Coarse Aggregate}

Crushed gravel taken from Al-Niba'ee region having the grading and properties shown in Table (5) and Table (6) respectively, is used. Results indicate that the used coarse aggregate complies with the requirements of the Iraqi Standard No.45/1984. as shown in Table 5.

Table 5. Grading of Coarse Aggregate

\begin{tabular}{ccc}
\hline Sieve Size $(\mathrm{mm})$ & Cumulative Passing (\%) & Limit of I.Q.S. No. 45/1984 \\
\hline 37.5 & 100 & 100 \\
20 & 96 & $95-100$ \\
10 & 48 & $30-60$ \\
5.0 & 4 & $0-10$ \\
\hline
\end{tabular}

Table 6. Physical Properties of Coarse Aggregate

\begin{tabular}{lll}
\hline Physical Properties & Test Results & Limit Specification \\
\hline Specific Gravity & 2.6 & - \\
Sulfate Content & $0.06 \%$ & $\leq 0.1 \%$ \\
Absorption & $0.75 \%$ & - \\
\hline
\end{tabular}




\subsection{Limestone Powder (LSP)}

This material is locally named as "Al-Gubra". It is a white grinded material from limestone. The particle size of the limestone powder conforms to EFNARC (2002). The chemical composition of LSP is shown in Table7.

Table 7. Chemical Compositions of (LSP) (ACI Committee 237R-07, ACI 237R-07)

\begin{tabular}{lc}
\hline Oxide composition & Content by Weight (\%) \\
\hline $\mathrm{CaO}$ & 54.10 \\
$\mathrm{MgO}$ & 0.13 \\
$\mathrm{SiO} 2$ & 1.38 \\
$\mathrm{Fe} 2 \mathrm{O} 3$ & 0.12 \\
$\mathrm{Al} 2 \mathrm{O} 3$ & 0.72 \\
$\mathrm{SO} 3$ & 0.21 \\
\hline
\end{tabular}

\subsection{Superplasticizer}

The superplasticizer used in the mix is adopted according to ASTM C494 types F and G (ASTM C-494/C 494M01), that is known commercially as "HP580". This type of plasticizer has been used to increases the workability and compaction. Properties of the superplasticizer are presented in Table (8).

Table 8. Properties of Superplasticizer [17]

\begin{tabular}{ll}
\hline Commercial Name & HP580 \\
\hline Appearance & Liquid (Light brown) \\
Specific gravity & $1.10 \pm 0.03$ \\
Chloride content & NIL- BS 5075/EN 934-2 \\
\hline
\end{tabular}

\subsection{Steel Bars Reinforcement}

Deformed steel bars of $(\phi 16 \mathrm{~mm})$ diameter were used as the main reinforcement for the nib zone for the control specimens and for flexural reinforcement of the beam. Bars of diameter $(\phi 10 \mathrm{~mm})$ were used as stirrups reinforcement of the beam and hanger zone. Also $(\phi 12 \mathrm{~mm})$ the bars were used in the nib zone for the reduced specimens. tests are achieved according to ASTM A370-2005 specifications, the test results are shown in Table (9).

Table9-Properties of Steel Bars

\begin{tabular}{ccc}
\hline Bar diameter $(\mathrm{mm})$ & Yield Stress * $(\mathrm{MPa})$ & Ultimate Stress $(\mathrm{MPa})$ \\
\hline 10 & 575 & 674 \\
12 & 600 & 694 \\
16 & 550 & 665 \\
\hline
\end{tabular}

\subsection{Mix Proportions of Self-Compacting Concrete}

Several trial mixes have been tested to produce a self-compacting mix with concrete cylinder compressive strength of $53 \mathrm{Mpa}$. Mix design of SCC met the requirements of filling and flow abilities, segregation resistance according to ACI Committee 237R-07. Table (11) indicates the mix proportions of the mix adopted in the present study.

\section{Description of Specimens}

For all specimens, the cross-section dimensions were the overall length was $(1600 \mathrm{~mm})(200 \mathrm{~mm})$ width, $(400 \mathrm{~mm})$ height, and. The nibs had a length of $(250 \mathrm{~mm})$ and an overall depth of $(200 \mathrm{~mm})$. The specimens have been divided into three groups, in group One the specimen is control and group Two included the specimens control reduced the reinforcement in nib and hanger region, and the third group included specimens were strengthening by near surface mounted (epoxy and steel bars), the shear span to effective depth ratio is $(\mathrm{a} / \mathrm{d}=1,1.5)$ for each group. Figure 1 shows typical detailing of the tested specimens. 
Table 10. Proportion of Concrete Mixes

\begin{tabular}{ll}
\hline Constituent material & Quantity $/ \mathrm{m}^{3}$ \\
\hline Cement $(\mathrm{kg} / \mathrm{m} 3)$ & 400 \\
Fine Aggregate $(\mathrm{kg} / \mathrm{m} 3)$ & 962 \\
Course Aggregate $(\mathrm{kg} / \mathrm{m} 3)$ & 780 \\
Limestone Powder $(\mathrm{kg} / \mathrm{m} 3)$ & 75 \\
Water $(\mathrm{kg} / \mathrm{m} 3)$ & 125 \\
Water/ Cement Ratio & 0.315 \\
Superplasticizer $(\mathrm{L} / \mathrm{m} 3)$ & 6 \\
\hline
\end{tabular}

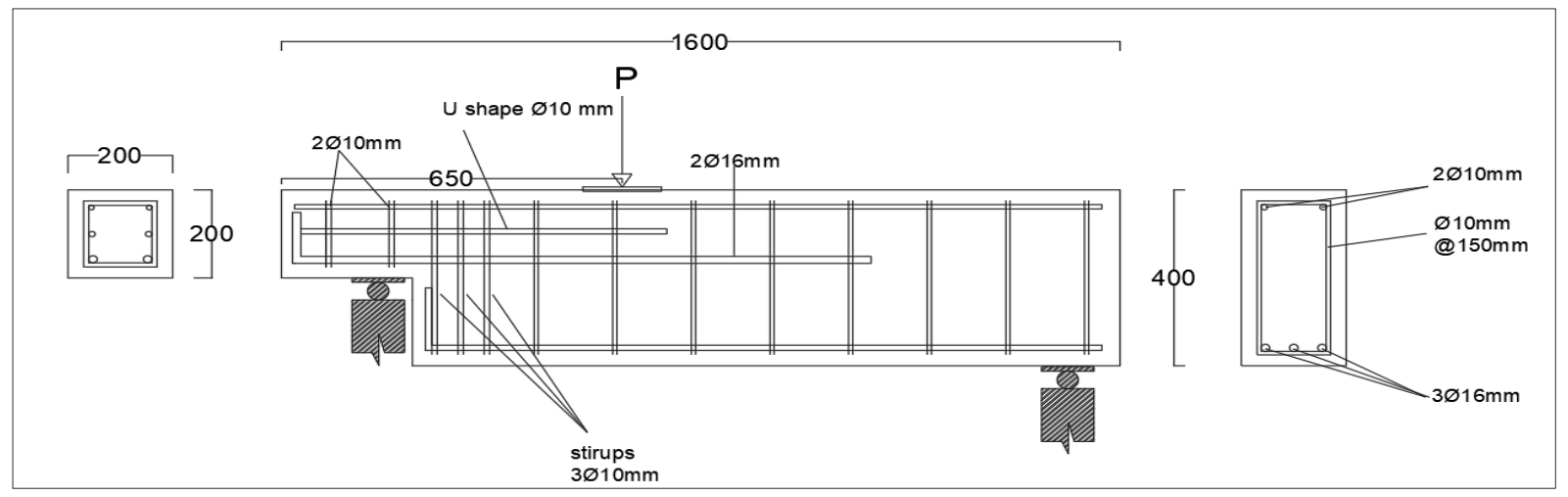

(a) Controls specimens
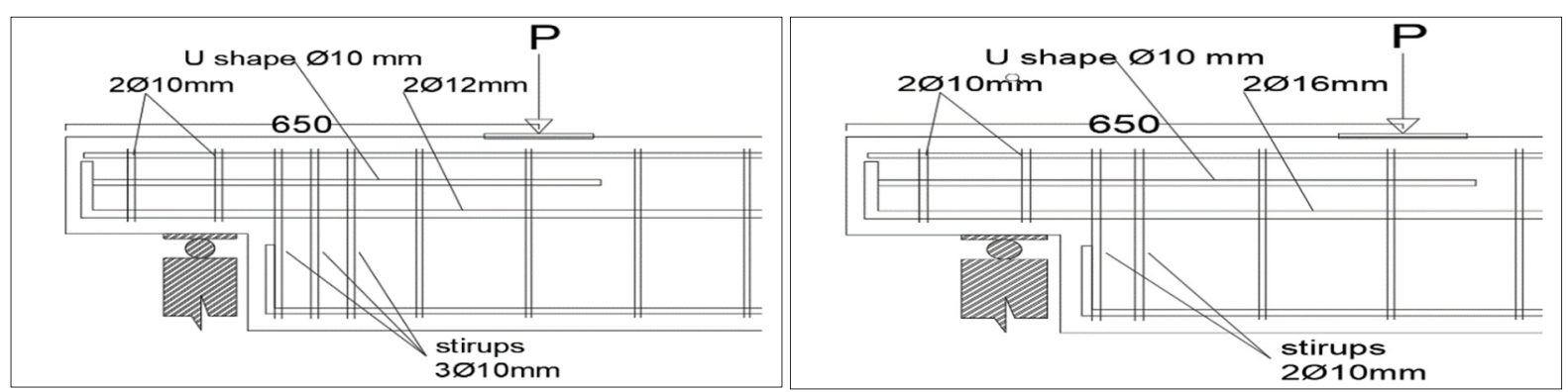

(b) Detailing of dapped ends with reduced hanger reinf.

(c) Detailing of dapped ends with reduced nib reinf.

Figure 1. Details of the dapped ends of the tested beams

Table 11. Details of Specimens

\begin{tabular}{llll}
\hline Group & Symbols & $\begin{array}{l}\text { a/d } \\
\text { Ratio }\end{array}$ & Reduction in reinforcement \\
\hline \multirow{2}{*}{ G1 } & C001 & 1 & Full reinforcement \\
& C002 & 1.5 & Full reinforcement \\
\hline \multirow{2}{*}{ G2 } & RN01 & 1 & $50 \%$ reduced nib reinforcement \\
& RN02 & 1.5 & $50 \%$ reduced nib reinforcement \\
& RH01 & 1 & $50 \%$ reduced hanger reinforcement \\
\hline
\end{tabular}

\section{Test Setup}

Each specimen was tested in a "universal testing machine at University of Kufa", at capacity of $(2000 \mathrm{kN})$. The tested beams are simply supported with span of $(1600) \mathrm{mm} \&(400 * 200) \mathrm{mm}$ for height to width of beams with $\mathrm{a} / \mathrm{d}$ ratio (1.0 and 1.5$)$ receptively. 
The Steel bearing plate has dimensions (100x200x10mm).The beams loaded with one-point load utilized and using roller support across the full width of the samples, as shown in Figure 2.

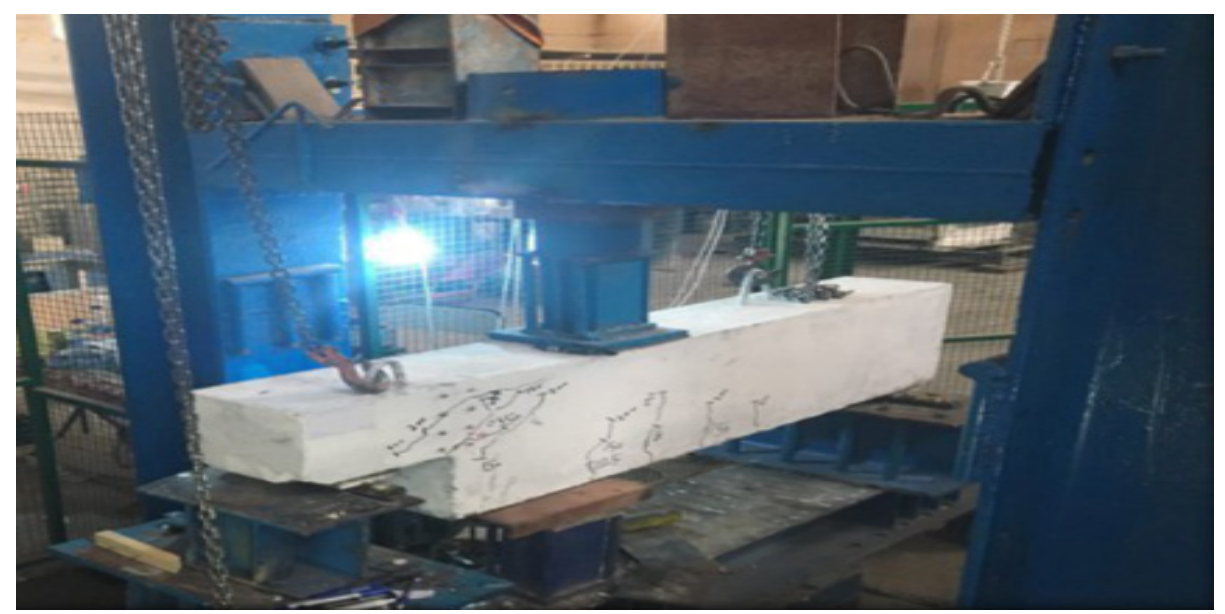

Figure 2. Supports and Loads Conditions

\section{Research Significance}

Investigate experimental the shear behavior and mode of failure of dapped end under effect of one-point loading with static load, Examining the effect of different variable including, shear span over depth (a/d) ratio,

\section{Experimental Results}

The results of the experimental tests of all reinforced concrete dapped end beams tested. as the first crack, failure load and the modes of failure are listed in Table (12). In all control beams, the first cracks initiated at the reentrant corner of dapped end. While in reduced beams, the first crack occurred at mid span of the beam, that developed diagonally or vertically towards the point load.

Table 12. Ultimate Loads and Failure Modes for the Beam Specimens

\begin{tabular}{|c|c|c|c|c|c|c|}
\hline \multirow[b]{2}{*}{ Groups } & \multicolumn{2}{|l|}{ a/d Ratio } & \multirow{2}{*}{$\begin{array}{l}\text { Shear } \\
\text { Cracking } \\
\text { Load }(\mathrm{kN})\end{array}$} & \multirow{2}{*}{$\begin{array}{l}\text { Ultimate } \\
\text { Load } \\
\mathrm{Pu}(\mathrm{kN})\end{array}$} & \multirow{2}{*}{$\begin{array}{l}\text { Max. } \\
\text { Deflection } \\
\text { (mm) }\end{array}$} & \multirow[t]{2}{*}{ Failure Mode } \\
\hline & & Symbols & & & & \\
\hline \multirow[b]{2}{*}{ G1 } & 1 & $\mathrm{C} 001$ & 65 & 371 & 9.1 & Diagonal shear at the Reentrant corner \\
\hline & 1.5 & $\mathrm{C} 002$ & 60 & 250 & 9.48 & $\begin{array}{l}\text { Diagonal shear at the extended end } \\
\text { Accompanied with crushing in } \\
\text { compression zone }\end{array}$ \\
\hline \multirow{3}{*}{ G2 } & 1 & RN01 & 60 & 330 & 8.13 & Diagonal shear at the extended end \\
\hline & 1.5 & $\mathrm{RN} 02$ & 65 & 238 & 9.7 & Diagonal shear at the reentrant end \\
\hline & 1 & RH01 & 70 & 350 & 8.83 & Diagonal shear at the extended end \\
\hline
\end{tabular}

\subsection{Control Specimens (C001, C002)}

These specimens are reinforced with full reinforcement, $(3-\Phi 10 \mathrm{~mm})$ stirrups for hanger zone and $(2-\Phi 16 \mathrm{~mm})$ as tension reinforcement in nib zone to show the effect of $(\mathrm{a} / \mathrm{d})$ ratio on the general response. The results are depicted in Figure 3. It can be concluded that reducing (a/d) value from (1.5) to (1.0) results in increasing the failure load capacity by about (32.6\%). Ductility is enhanced from (1.72) for specimen C001 to (1.93) for specimen C002 i.e. improvement by (11\%). Figure 4a shows the cracking pattern for the specimen C001 at failure. the first crack initiated within the reentrant corner at load level of $65 \mathrm{kN}$. With further load, more cracks initiated and developed diagonally to the compression zone. At load level of $120 \mathrm{kN}$; the first flexural crack initiated. At load level of (180 $\mathrm{kN})$, the first reentrant diagonal crack penetrates most of the nib depth. The failure occurred at load of (371 $\mathrm{kN})$ following diagonal shear cracking at the reentrant corner. The cracking propagation at failure instant for the specimen C002 is depicted in Figure 4b. the initiation of the first cracking is recorded at the reentrant corner as in C001 within nearly the same load level. With further load, cracking penetrates diagonally, and beam takes to rotate as two rigid elements. some crushing is developed at the compression zone within load level of $(200 \mathrm{kN})$. At 
loading stage of $125 \mathrm{kN}$; the first flexural crack occurred. The beam failed at load level of $(250 \mathrm{kN})$ due the reentrant diagonal cracking combined with the spalling of the top compression concrete layer.

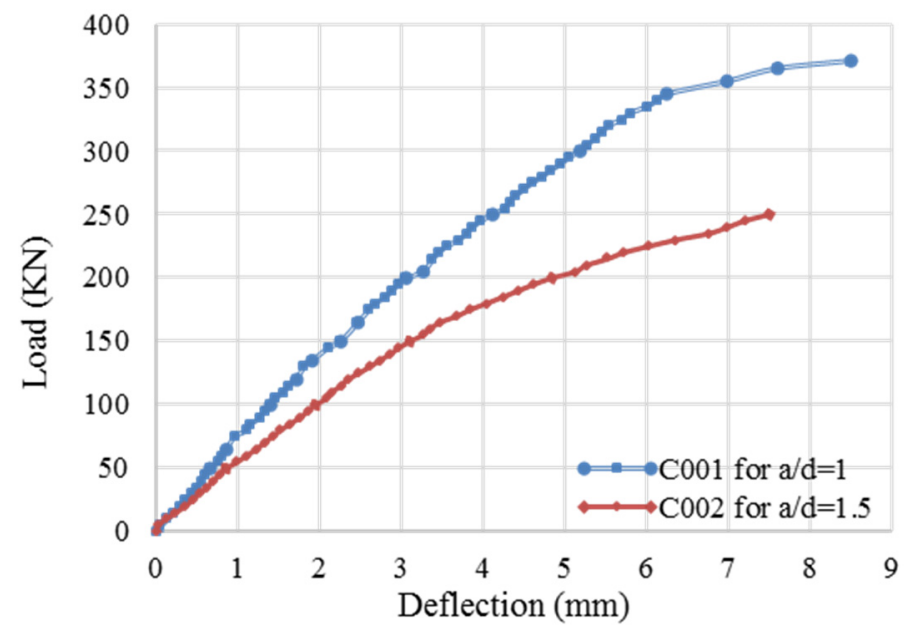

Figure 3. Load Deflection response of the Control Specimens with Different (a/d) Ratio

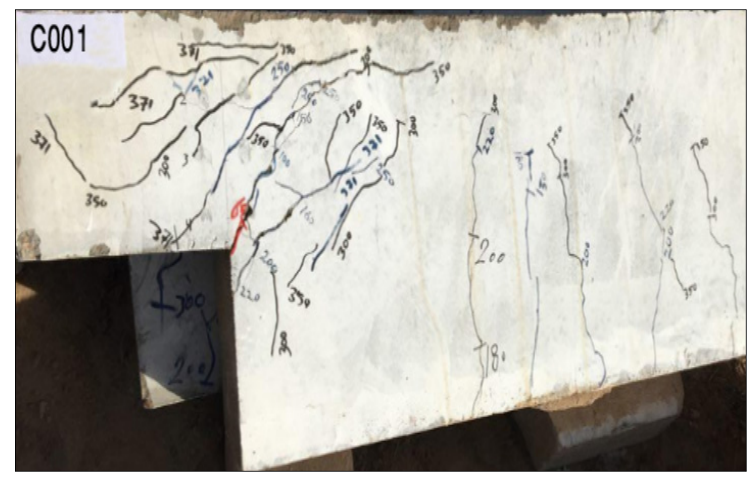

(a) Specimen $\mathrm{C} 001$

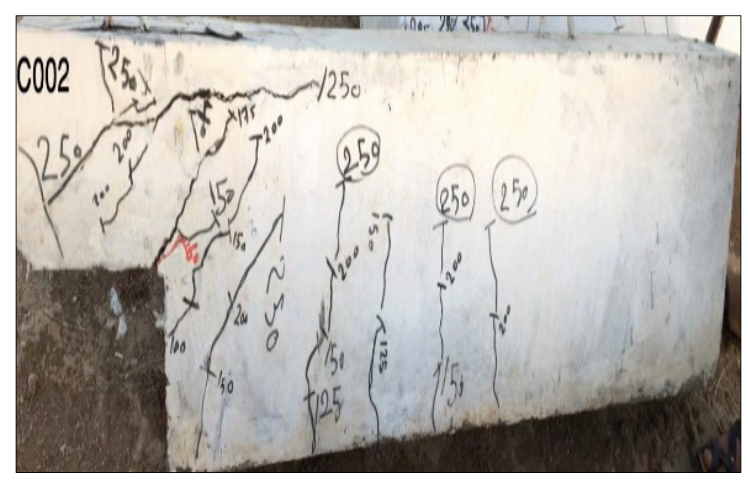

(b) Specimen C002

Figure 4. Cracks Patterns at failure for the Control Specimens

\subsection{Specimens Control Reduced Reinforcement (RN01 \& RNO2)}

To study the effect of reducing the nib reinforcement on the behavior of dapped ends, two specimens RN01 \& RN02 have been tested with the same reinforcement of the control specimens C001 \& C002, except that $(2-\varnothing 12 \mathrm{~mm})$ instead of $(2-\varnothing 16 \mathrm{~mm})$ as a nib reinforcement, i.e. about $50 \%$ reduction. Load deflection curves are plotted against the control specimen, the results are shown in Figures 5 and 6. Results reveal that the reduction in nib reinforcement led to a decrease in the failure load and deflection about (12.2\%) and (12\%), respectively for specimen RN01 and RN02. In addition, it is found that the specimen RN01 has a small effect of reducing the nib reinforcement of the dapped end with $(\mathrm{a} / \mathrm{d}=1.0)$, where, a reduction in the failure load and deflection about $(12.4 \%)$ and $(5 \%)$, respectively. The small differences between the control specimens (with full nib reinforcement) and the specimens of reduced reinforcement may be attributed as that the PCI method overestimates the steel amounts with selfcompacting high strength concrete and there is a need to introduce some modifications on the method to treat high strength concrete dapped end beams. For specimens C001 and RN01, comparing Figure 4a with Figure 6a the same pattern of crack propagation can be seen. Also, the two specimens failed by the reentrant diagonal cracking mode. For specimens C002 and RN02 as in Figure $4 \mathrm{~b}$ and $6 \mathrm{~b}$ the same can be said and the two beams followed the same mode of failure i.e. reentrant diagonal cracking accompanied by crashing in compression zone.

This insures the need for more studies to check if the PCI method need to be revised to include type of concrete (i.e. the self-compacting high strength concrete) in the design steps of the method. 


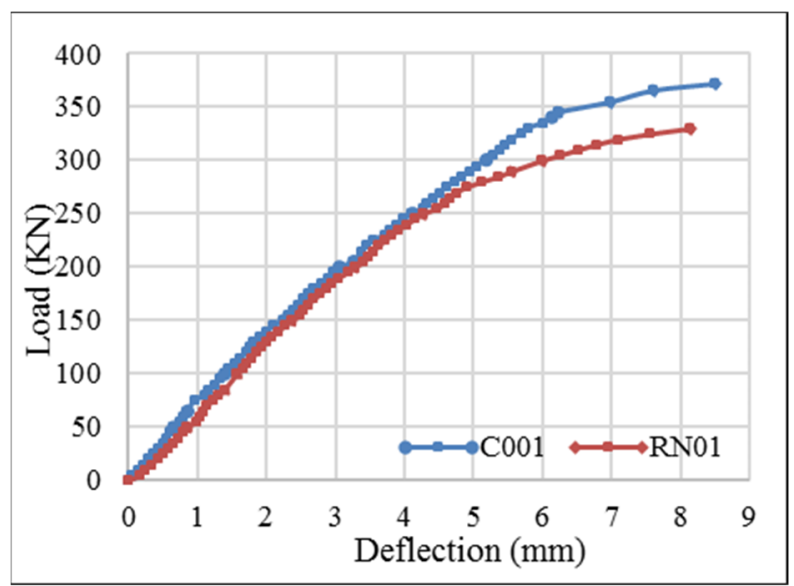

a) load deflection response of RNO1 against $\mathrm{C} 001$

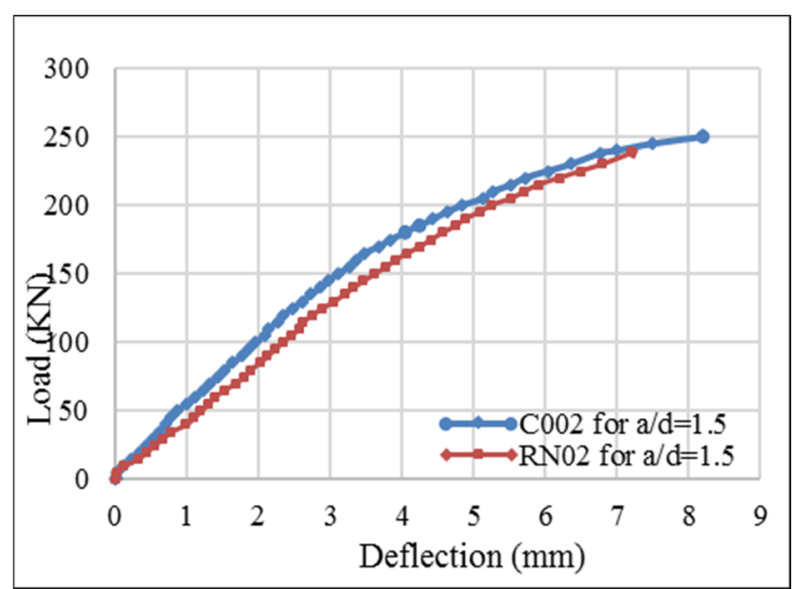

b) load deflection response of $\mathrm{RNO} 2$ against $\mathrm{C} 002$

Figure 5. Effect of Reduction Nib Reinforcement with Different values of (a/d) Ratio

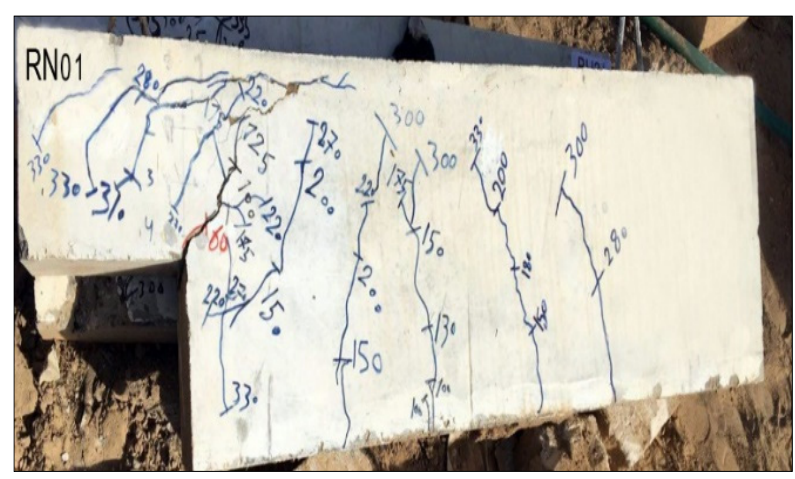

(a) specimenRN01

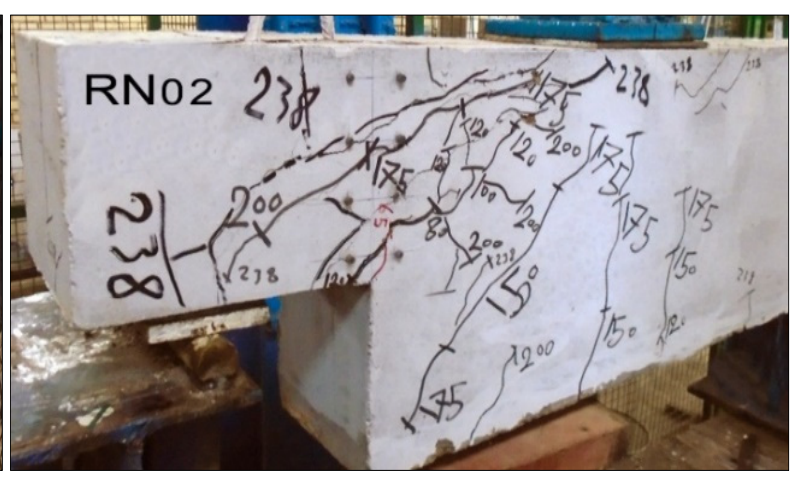

(b) specimen RN02

Figure 6. Cracks Patterns for the Specimens with Reduced Reinforcement at Nib region

\subsection{Specimen Control Reduced Reinforcement (RH01)}

In this specimen All the steel is kept the same as control specimen expect that at hanger reinforcement $(2-\varnothing 10 \mathrm{~mm})$ stirrups were used i.e. about 33\% reduction. the load-deflection curve against specimen C001 is shown in Figure 7 and the cracking pattern is shown in Figure 8, The failure of this specimen occurred by diagonal shear failure in the reentrant corner after that change the failure mode to extended end at load about ( $350 \mathrm{KN})$ as shown in the Figure 7. It can be noticed that the reduction in hanger reinforcement results in a slight reduction of the failure load by about $(6 \%)$, and higher deflection at failure about $(18 \%)$ as shown in Figure 8 . There is no significant reduction in beam capacity due to deficient amount of hanger steel. This may be attributed to the fact that the concrete resist most of the shear stresses produced within the dapped end region. Then, the steel of the hanger will be less effective than the case of dapped ends with normal strength concrete. Also, comparing crack pattern for specimen RH01, Figure 9, with that for specimen C001, Figure 5a. it is obvious that specimen RH01 failed by the same mode of failure as in $\mathrm{C} 001$ but with some crashing at compression face close to the point of load application. 


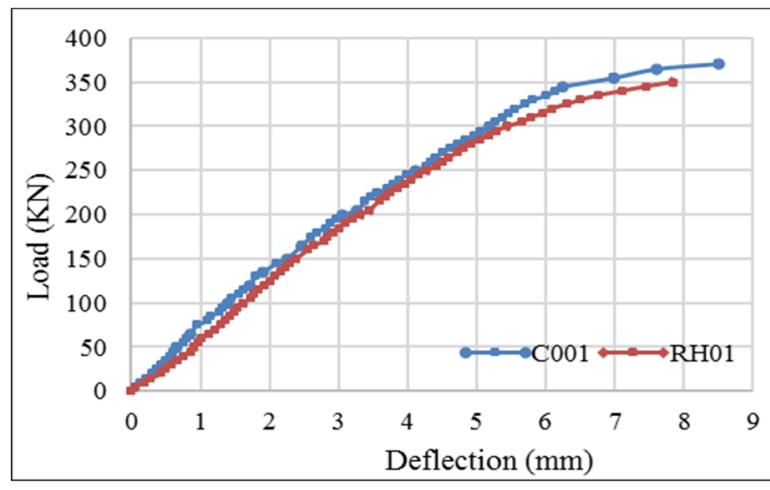

Figure 7. Load-Deflection response of Specimen (RH01) against (C001)

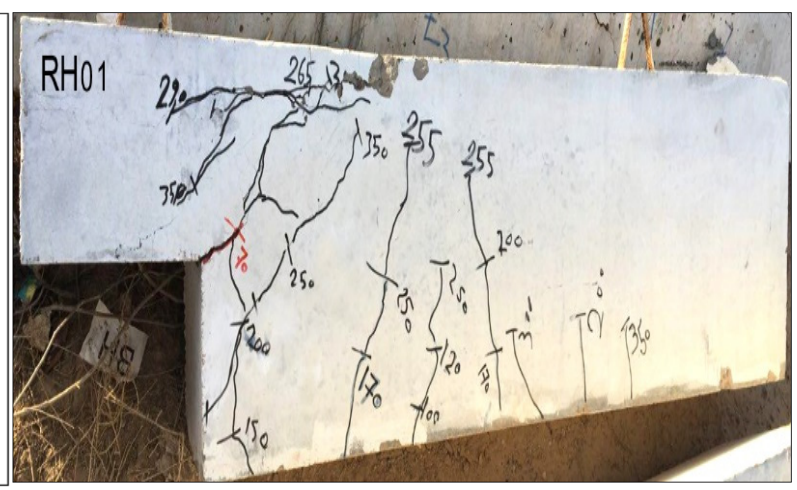

Figure 8. Cracks Patterns for the Specimen with Reduced Reinforcement at Hanger

\section{Conclusions}

It found that $(\mathrm{a} / \mathrm{d})$ ratio has a noticeable effect on behavior of dapped end beam. For the tested control specimens (with full-reinforcement), the reduction of (a/d) ratio from (1.5) to (1.0), led to increase the failure load capacity by about (32.6\%) and shifting the mode of failure from diagonal tension in the extended end to Diagonal shear failure at the reentrant corner accompanied with crushing in compression zone. Also, it was observed that the reduction of nib reinforcement by about (50\%). Also, the reduction of hanger reinforcements by about (40\%), has decreased failure load by about $(6 \%)$ in the $(\mathrm{a} / \mathrm{d})$ ratio $(1.0)$. has no essential effect on failure load i.e. reduction of about $(5 \%)$ for $\mathrm{a} / \mathrm{d}=1.5$ and $(12.4 \%)$ for $\mathrm{a} / \mathrm{d}=1.0$. This may be attributed that the PCI method yields some overestimation when design the self-compacting high strength concrete.

The reducing of reinforcing steel in (NIB) region for high-resistance concrete, equipped with limiting factors and encircling enough, will not weaken the specimen very much

\section{References}

ACI Committee 237R-07, ACI 237R-07 Self-Consolidating Concrete. Farmington Hills, Michigan; American Concrete Institute. 2007.

Ahmad, S., Elahi, A., Hafeez, J., Fawad, M., \& Ahsan, Z. (2013). Evaluation of the Shear Strength of Dapped Ended Beam. Life Science Journal, 10(3), 1038-1044.

ASTM A 370-05 (2005). Standard Test Method and Definite on for Mechanical Testing of Steel Products. Annual Book of ASTM Standards, 1(1), ASTM, Philadelphia, PA. https://doi.org/10.1520/A0370-05

ASTM C-494/C 494M -01. (2001). Standard Specification for Chemical Admixtures for Concrete. Annual Book of American Society for Testing and Materials, 2001. https://doi.org/10.1520/C0494_C0494M-99AE01

Aswin, M., Mohammed, B. S., Liew, M. S., \& Syed, Z. I. (2015). Shear Failure of RC Dapped-End Beams. Hindawi Publishing Corporation Advances in Materials Science and Engineering, 2015. https://doi.org/10.1155/2015/309135

Atta, A., \& Taman, M. (2016). Innovative method for strengthening dapped-end beams using an external prestressing technique. Materials and Structures, 49(2016), 3005-3019. https://doi.org/10.1617/s11527-0150701-8

EFNARC. (2002). Specification and Guidelines for Self-Compacting Concrete. Association House, 99 West Street, Farnham, Surrey, London, UK, February 2002, 32pp. Retrieved from http://www.efnarc.org/pdf/SandGforSCC.PDF

Herzinger, R., \& Elbadry, M. (2007). Alternative reinforcing details in dapped ends of precast concrete bridge girders: experimental investigation [J]. Transportation Research Record: Journal of the Transportation Research Board, 2007(2028), 111-121. https://doi.org/10.3141/2028-13

Iraqi Specification No. 45. (1984). Natural Sources for Gravel that is Used in Concrete and Construction. Baghdad. Iraqi Specification No. 5. (1984). Portland Cement, Baghdad.

Liem, S. K. (1983). Maximum Shear Strength of Dapped-end or Corbel. MSc Thesis, College of Engineering, University Concordia, Montreal, Quebec, Canada, August 1983. 
Lu, W., Lin, I., Hwang, S., \& Lin, Y. (2003). Shear strength of high strength concrete dapped-end Beams. Journal of the Chinese Institute of Engineers, 26(5), 671-680. https://doi.org/10.1080/02533839.2003.9670820

Mattock, A. H., \& Chan, T. C. (1979). Design and Behavior of dapped End Beams. PCI Journal, 24(6), 28-45. https://doi.org/10.15554/pcij.11011979.28.45

Nanni, A., \& Huang, P. C. (2002). Validation of an Alternative Reinforcing Detail for the Dapped Ends of Pestressed Double Tees. University of Missouri-Rolla 224 Engineering Research Laboratory, PCI Journal 2002.

Precast Prestressed Concrete Institute. (2010). PCI Design Handbook: Precast and Prestressed Concrete 7th Ed. (7th ed.). Chicago, IL.

\section{Copyrights}

Copyright for this article is retained by the author(s), with first publication rights granted to the journal.

This is an open-access article distributed under the terms and conditions of the Creative Commons Attribution license (http://creativecommons.org/licenses/by/4.0/). 